Check for updates
OPEN ACCESS

\section{Sugary drink consumption and risk of cancer: results from NutriNet-Santé prospective cohort}

\author{
Eloi Chazelas, ${ }^{1}$ Bernard Srour, ${ }^{1}$ Elisa Desmetz, ${ }^{1}$ Emmanuelle Kesse-Guyot, ${ }^{1}$ Chantal Julia, ${ }^{1,2}$ \\ Valérie Deschamps, ${ }^{3}$ Nathalie Druesne-Pecollo, ${ }^{1}$ Pilar Galan, ${ }^{1}$ Serge Hercberg,,${ }^{1,2}$ \\ Paule Latino-Martel, ${ }^{1}$ Mélanie Deschasaux, ${ }^{1}$ Mathilde Touvier ${ }^{1}$
}

${ }^{1}$ Sorbonne Paris Cité

Epidemiology and Statistics

Research Center (CRESS),

Inserm U1153, Inra U1125,

Cnam, Paris 13 University,

Nutritional Epidemiology

Research Team (EREN), 74

rue Marcel Cachin F-93017

Bobigny Cedex, France Avicenne Hospital, AP-HP,

Bobigny, France

${ }^{3}$ Santé Publique France, The French Public Health Agency, Nutritional Epidemiology

Surveillance Team (ESEN)

Bobigny, France

Correspondence to: B Srour b.srour@eren.smbh.univ-paris13.fr (or @BernardSrour on Twitter: ORCID 0000-0002-1277-3380) Additional material is published online only. To view please visit the journal online.

Cite this as: BMJ 2019;365:12408 http://dx.doi.org/10.1136/bmj.l2408

Accepted: 7 May 2019
${ }^{2}$ Public Health Department,

\section{ABSTRACT}

OBJECTIVE

To assess the associations between the consumption of sugary drinks (such as sugar sweetened beverages and $100 \%$ fruit juices), artificially sweetened beverages, and the risk of cancer.

\section{DESIGN}

Population based prospective cohort study.

\section{SETTING AND PARTICIPANTS}

Overall, 101257 participants aged 18 and over (mean age 42.2, SD 14.4; median follow-up time 5.1 years) from the French NutriNet-Santé cohort (2009-2017) artificially sweetened beverages were assessed by using repeated 24 hour dietary records, which were designed to register participants' usual consumption for 3300 different food and beverage items.

\section{MAIN OUTCOME MEASURES}

Prospective associations between beverage consumption and the risk of overall, breast, prostate, and colorectal cancer were assessed by multiadjusted Fine and Gray hazard models, accounting for competing risks. Subdistribution hazard ratios were computed.

\section{RESULTS}

The consumption of sugary drinks was significantly associated with the risk of overall cancer $(n=2193$ cases, subdistribution hazard ratio for a $100 \mathrm{~mL} / \mathrm{d}$ increase $1.18,95 \%$ confidence interval 1.10 to 1.27 , $P<0.0001)$ and breast cancer $(693,1.22,1.07$ to 1.39 , $\mathrm{P}=0.004)$. The consumption of artificially sweetened beverages was not associated with the risk of cancer. In specific subanalyses, the consumption of $100 \%$ fruit juice was significantly associated with the risk of overall cancer $(2193,1.12,1.03$ to $1.23, \mathrm{P}=0.007)$. were included. Consumptions of sugary drinks and

\section{WHAT IS ALREADY KNOWN ON THIS TOPIC}

The consumption of sugary drinks has increased worldwide during the last decades

Sugary drinks are convincingly associated with the risk of obesity, which is a strong risk factor for many cancers

\section{WHAT THIS STUDY ADDS}

The consumption of sugary drinks (including $100 \%$ fruit juice) was associated with an increased risk of overall cancer and breast cancer

In specific subanalyses, the consumption of $100 \%$ fruit juices were also associated with an increased risk of overall cancers

The consumption of artificially sweetened beverages was not associated with a risk of cancer, but statistical power was probably limited owing to a relatively low consumption in this sample

\section{CONCLUSIONS}

In this large prospective study, the consumption of sugary drinks was positively associated with the risk of overall cancer and breast cancer. $100 \%$ fruit juices were also positively associated with the risk of overall cancer. These results need replication in other large scale prospective studies. They suggest that sugary drinks, which are widely consumed in Western countries, might represent a modifiable risk factor for cancer prevention.

\section{STUDY REGISTRATION}

ClinicalTrials.gov NCT03335644.

\section{Introduction}

The consumption of sugary drinks has increased worldwide in the last decades; according to the Global Burden of Disease, ${ }^{1}$ their "summary exposure value" (taking into account the extent of exposure by risk level and the severity of that risk's contribution to disease burden)increased by more than 40\% from 1990 to 2016. The impact of sugary drinks on cardiometabolic health is well studied: ${ }^{2}$ they are associated with an increased risk of weight gain, being overweight, or obesity; ${ }^{34} \mathrm{a}$ greater incidence of type 2 diabetes (independently of adiposity); ${ }^{5}$ a higher risk of hypertension; ${ }^{6}$ and with cardiometabolic death. ${ }^{7}$ In 2010, Singh and colleagues estimated that among all worldwide yearly deaths from diabetes and cardiovascular diseases, about 178000 were attributable to sugary drink consumption. ${ }^{8}$ Sugary drink consumption was one of the behavioural risk factors that contributed the most to the increase in global attributable deaths and disability adjusted life years (DALYs) between 1990 and 2016. ${ }^{1}$ Artificially sweetened beverages were initially envisioned as a healthier alternative, however, they are associated with a higher incidence of hypertension, ${ }^{9}$ obesity, ${ }^{10}$ and type 2 diabetes. ${ }^{5}$ Besides, some artificial sweeteners were suggested to increase glucose intolerance by altering the gut microbiota. ${ }^{11}$

In contrast, the association between sugary drinks and the risk of cancer has been less investigated. However, this potential relation raises increasing concerns owing to its mechanistic plausibility. Indeed, sugary drinks are convincingly associated with the risk of obesity, ${ }^{34}$ which in turn, is recognised as a strong risk factor for many cancers. ${ }^{12}$ Apart from the obesity and adiposity pathways, mechanisms underlying a link between sugary drinks and cancer might involve insulin resistance caused by their high glycaemic index or glycaemic load, which have been related to breast cancer, ${ }^{13} 14$ hepatocellular cancer, ${ }^{15}$ and diabetes related carcinomas. ${ }^{16}$ The chemical compounds in 
sugary drinks, such as 4-methylimidazole in drinks containing caramel colourings (defined as possibly carcinogenic to humans by the International Agency for Research on Cancer, IARC), ${ }^{17}{ }^{18}$ pesticides in fruit juices, ${ }^{19}{ }^{20}$ or artificial sweeteners such as aspartame might play a role in carcinogenesis. ${ }^{21}$

However, epidemiological literature on sugary drinks and the risk of cancer is still limited and there was not enough evidence to support a link in the recent report by the World Cancer Research Fund/American Institute for Cancer Research. ${ }^{12}$ Very few prospective studies have been conducted on the association between sugary drinks and individual cancer site. Two prospective cohorts published contrasting results regarding breast cancer: one suggesting an increased risk in post-menopausal women (Melbourne Collaborative Cohort Study, 946 cases), ${ }^{22}$ and the other observing no association (Framingham Offspring cohort, 124 cases). ${ }^{23}$ Increased risks were also suggested for adiposity related and obesity related cancers in recent surveys, ${ }^{22} 23$ as well as for pancreas, ${ }^{24}$ gallbladder, ${ }^{25}$ and endometrial cancers, ${ }^{26}$ although some other studies observed null results. ${ }^{12} 27-29$ Thus, literature concerning sugary drinks and the risk of cancer is inconsistent and needs further explorations. Furthermore, sugary drinks and artificially sweetened beverages were rarely analysed separately in previous studies. Thus, the aim of this study is to investigate the relations between the consumptions of sugary drinks and artificially sweetened beverages and the risk of first cancer in a large prospective cohort with detailed and up to date dietary intake assessment.

\section{Methods}

\section{Study population}

NutriNet-Santé is a French, ongoing, web-based cohort launched in 2009 aiming to study the associations between nutrition and health as well as the determinants of dietary behaviours and nutritional status. This cohort has been previously described in detail. ${ }^{30}$ Participants aged over 18 with access to the internet have been continuously recruited from the general population since May 2009 by means of large multimedia campaigns. Questionnaires are completed online on a dedicated website. Participants are followed by using an online platform connected to their email address. The NutriNet-Santé study is registered at ClinicalTrials.gov as NCT03335644.

\section{Data collection}

At inclusion, participants completed a set of five questionnaires related to sociodemographic and lifestyle characteristics (eg, date of birth, sex, educational level, smoking status, number of children), ${ }^{31}$ anthropometry (height, weight), ${ }^{32}{ }^{33}$ dietary intakes (see below), ${ }^{3435} 36$ physical activity (validated seven day International Physical Activity Questionnaire), ${ }^{37}$ and health status (eg, personal and family history of diseases, menopausal status, drug use including hormonal treatment for menopause and oral contraceptives). Weight was collected every six months.
The web-based self administered anthropometric questionnaire was compared with a traditional paper questionnaire, ${ }^{33}$ and reported weight was also validated against weight measured with a calibrated scale (BC418MA, TANITA, Tokyo, Japan) by trained investigators in a validation study on a subsample, ${ }^{32}$ showing high consistency. Other web-based questionnaires used to collect baseline characteristics of the participants (eg, sociodemographic and lifestyle data) have also been tested against traditional paper questionnaire, ${ }^{31}$ showing very high consistency between the two methods, and even a lower proportion of missing or abnormal values in the web questionnaire, owing to integrated controls, mandatory fields, and conditional skip patterns. Other methodological studies were conducted to test for the reliability of the data declared online by the participants and also observed very high levels of consistency. ${ }^{38}$ For instance, the consistency between declared information on sex, date of birth, and department of birth of a sample of participants and the first digits of their social security number was checked.

Regarding dietary data collection, at baseline and every six months (to vary the season of completion), participants were asked to fill three non-consecutive validated web-based 24 hour dietary records, randomly assigned over a two week period (two weekdays and one weekend day in order to take into account the variability of the diet during the week). The calculation of the mean daily dietary intake across the study period was weighted in order to respect the 5:7 and 2:7 ratios of week days and weekend days. ${ }^{34} 3539$ At least two 24 hour dietary records during the first two years of follow-up were mandatory in order to be included in the nutritional analyses. Appendix 1 shows the details on qualitative and quantitative assessment of food and beverage intake performed in NutriNetSanté. Dietary under-reporting was identified on the basis of the method proposed by Black, by using the basal metabolic rate and Goldberg cut-off, and underreporters of energy intake were excluded $(20.0 \%) .^{40}$ Appendix 2 shows the details on the method for detection of under-reporters.

\section{Beverage consumption}

The NutriNet-Santé composition table included 97 sugary drink items and 12 artificially sweetened beverage items. The sugary drinks group consisted of all sugar sweetened beverages containing more than $5 \%$ of simple carbohydrates, as well as $100 \%$ fruit juices (with no added sugar). It included soft drinks (carbonated or not), syrups, 100\% juice, fruit drinks, sugar sweetened hot beverages, milk-based sugar sweetened beverages, sport drinks, and energy drinks. Median sugar content for sugary drinks was $10.7 \mathrm{~g} / 100 \mathrm{~mL}$. The sugary drinks group was then subdivided into $100 \%$ fruit juices (median sugar level $10.3 \mathrm{~g} / 100 \mathrm{~mL}$ ) and sugary drinks except 100\% fruit juices (median sugar level $10.9 \mathrm{~g} / 100 \mathrm{~mL}$ ). The group artificially sweetened beverages included all beverages containing non-nutritive sweeteners, such as diet 
soft drinks, sugar-free syrups, and diet milk-based beverages.

Biological sampling and clinical examination Participants in the NutriNet-Santé study were invited, on a voluntary basis, for a visit in one of the local centres specifically set up for biological sampling and clinical examination, including bioimpedance measurements, in each region (83 hospital centres). A visceral fat index was calculated with a calibrated impedance body composition analyser (BC-418MA, TANITA, Tokyo, Japan), based on total body and regional $\%$ fat estimations which were previously validated against dual-energy X-ray absorptiometry. ${ }^{41}$ More generally, fat estimates by body composition analyser were validated against dual-energy X-ray absorptiometry in several studies. ${ }^{42} 43$ The visceral fat index ranges from 0 to 60 units, and is considered excessive when over 12 units. These biological and clinical data were collected for 19772 participants of the cohort, among which 15637 pertained to the study sample of the present study.

\section{Case ascertainment}

Health events were self declared through a yearly questionnaire, a specific check-up questionnaire (every three months), or at any time through a specific interface on the study website. Each declaration of incident cancer was controlled by a physician from the study team who contacted participants and asked them to provide any relevant medical records. When additional information was needed, we contacted the patient's physician, or hospital, or both. All medical data was reviewed by a committee of physicians. The NutriNet-Santé cohort is linked to medico-administrative databases of the national health insurance system (SNIIRAM databases) and to the French national cause specific mortality registry (CépiDC). Based on these databases, we could complete information regarding health events and deaths, thereby limiting any potential bias owing to participants with cancer who might not report their disease to the study investigators. Cancer cases were classified by using the ICD-10 (international classification of diseases, 10th revision). In this study, we considered all first primary cancers diagnosed between the inclusion date and 11 January 2018 to be cases, except for basal cell skin carcinoma, which was not considered as a cancer. Medical records were obtained for more than $90 \%$ of cancer cases. Because of the high validity of self reports ( $95 \%$ of self reported cancers for which a medical record was obtained were confirmed by our physicians), all participants who self reported incident cancers were included as cases, unless they were identified as non-case participants by a pathology report.

\section{Statistical analysis}

We defined baseline as the date of inclusion in the cohort (when participants finished completing the set of baseline questionnaires on diet, physical activity, health, sociodemographic characteristics, and anthropometry). We included 101257 participants without cancer at baseline who provided at least two valid 24 hour dietary records during their first two years of follow-up. Appendix 3 shows the study flow. Appendix 4 compares included with excluded participants.

We performed variance reduction by calculating usual daily beverage intakes with the method proposed by the US National Cancer Institute (SAS macros \%MIXTRAN followed by \%INDIVINT) to correct for within person and between person variability and to deal with zeroes (non-consumption). ${ }^{44}$ We calculated daily dietary intakes in this prospective analysis by taking into account all 24 hour dietary records available during the first two years of each participant's follow-up and used these as baseline usual dietary intakes. We used the Multiple Imputation by Chained Equations method by fully conditional specification (15 imputed datasets) to handle missing data in covariates for the following variables: smoking status ( $0.1 \%$ of missing data), level of education $(6.3 \%)$, physical activity level (14.0\%), height (0.6\%), and BMI $(0.6 \%) .{ }^{45}$ We estimated weight gain during follow-up as the percentage of weight gain between inclusion of participants and the last weight declared to date (excluding weight data reported during the two years preceding a patient developing cancer). We defined sex specific quarters of consumption for each type of sugary drink. Participants were included at different entry dates, had different follow-up durations, and censored data. Studied cancers were overall, breast, prostate, and colorectal cancers (the most frequent cancer sites in the cohort), and lung cancer in the secondary analyses.

Since the main objective was to compare the risk of cancer across different levels of sugary drink consumption (coded as continuous variables or quarters) while accounting for competing events (mortality and other cancer sites than the one studied in cancer site-specific analyses), we used multivariable Fine and Gray models with age as the primary time scale and a left truncation to compute subdistribution hazard ratios and their 95\% confidence intervals.

This model estimates the absolute incidence of the event of interest, allowing us to model directly the association between the exposure variable and the rate of cancer after accounting for competing risks and allowing a direct (but non-numeric) inference on the risk of cancer. ${ }^{46} 47$ Thus, subdistribution hazard ratios can be interpreted as the change in cancer rate according to sugary drink consumption, in patients who are either event-free or who have experienced a competing event: ${ }^{48}$ a subdistribution hazard ratio significantly $>1$ reflects an increased risk and a subdistribution hazard ratio significantly $<1$ reflects a decreased risk. As a sensitivity analysis, another approach to take into account competing risk was tested using cause-specific Cox models, providing cause-specific hazard ratios.

We tested the proportional hazard assumption of the Fine and Gray model by using rescaled Schoenfeld- 
type residuals computed along with the SAS macro \%PSHREG as described by Kohl and colleagues. ${ }^{49}$ The corresponding $\mathrm{P}$ values were obtained by testing Pearson correlations between residuals and log (follow-up duration) (appendix 5).

In continuous models, the increment for the different beverage types was adapted according to the distribution of their consumption. An increment of $100 \mathrm{~mL} / \mathrm{d}$ was adapted for sugary drinks, but it was excessive for artificially sweetened beverages regarding their range of consumption in this study (as shown in distribution plots, appendix 6). Thus, an increment of $10 \mathrm{~mL} / \mathrm{d}$ was selected for artificially sweetened beverages. The increment for sugar from sugary drinks was $10 \mathrm{~g} / \mathrm{d}$.

We assessed and tested the potential nonlinear effects of continuous exposure variables by using restricted cubic spline transformations in multivariable models of competing endpoints (appendix 7).50 Participants contributed person time until the date of diagnosis of cancer, the date of last completed questionnaire, the date of death, or 11 January 2018, whichever occurred first. We performed stratifications by menopausal status for breast cancer analyses. For these, women contributed person time to the premenopausal model until their age at menopause and to the postmenopausal model from their age at menopause.

The main model was adjusted for age (time scale), sex, energy intake without alcohol (kcal/d, continuous), sugar intake from other dietary sources (all sources except sugary drinks), alcohol, sodium, lipid and fruit and vegetable intakes ( $\mathrm{g} / \mathrm{d}$, continuous), body mass index $\left(\mathrm{kg} / \mathrm{m}^{2}\right.$, continuous), height $(\mathrm{cm}$, continuous), physical activity (high, moderate, low, calculated according to International Physical Activity Questionnaire recommendations), ${ }^{37}$ smoking status (never, former, current smokers), number of 24 hour dietary records (continuous), family history of cancer (yes or no), educational level (less than high school degree, less than two years after high school degree, two or more years after high school degree), and the following prevalent conditions at baseline: type 2 diabetes (yes or no), hypertension (yes or no), major cardiovascular event (myocardial infarction or stroke; yes or no), and dyslipidaemia (triglycerides or cholesterol, or both; coded as 0 , 1 , 2, according to the number of dyslipidaemia). We made additional adjustments for the number of biological children (continuous), menopausal status at baseline (menopausal or non-menopausal), hormonal treatment for menopause at baseline and during follow-up (for postmenopausal analyses; yes or no), and oral contraception use at baseline and during follow-up (for premenopausal analyses; yes or no) for breast cancer analyses.

We performed stratified analyses according to baseline BMI status $\left(<\right.$ or $\geq 25 \mathrm{~kg} / \mathrm{m}^{2}$ ) and percentage weight gain since baseline $(\leq$ or $>5 \%)$. Since some antioxidants might interact with tobacco smoke, ${ }^{51}$ we tested the interaction between fruit juice intake (as well as other types of sugary drinks) and smoking status on the risk ofcancer. We tested other exposure variables in multivariable models, such as energy intake from sugary drinks, as well as sugar sweetened sodas. We applied a bootstrap approach to the estimation of usual dietary intakes by variance reduction as sensitivity analysis, followed by testing Fine and Gray models to account for extra variation. Lower and upper bounds of empirical confidence intervals were defined respectively as the 2.5th and 97.5th centiles of the distribution of subdistribution hazard ratios obtained across all iterations $(n=200)$. Appendix 11 shows the methods and results of a series of other sensitivity analyses.

We performed multivariable linear regression as a secondary analysis in order to investigate the association between quarters of consumption of sugary drinks and visceral adiposity index, taking into account potential confounders: age, sex, energy intake without alcohol, sugar intake from other dietary sources, alcohol intake, body mass index, physical activity, smoking status, number of 24 hour dietary records and educational level.

All tests were two sided, with $\mathrm{P}<0.05$ considered to be statistically significant. We used SAS version 9.4 for the analyses.

\section{Patient and public involvement}

The research question developed in this article corresponds to a strong concern of the participants involved in the NutriNet-Santé cohort, and of the general public. The results of the present study will be disseminated to the NutriNet-Santé participants through the cohort website, public seminars, and a press release.

\section{Results}

\section{Description of the study population}

A total of 101257 participants (21533 (21.3\%) men and $79724(78.7 \%)$ women) were included in the analyses. Mean age at baseline was 42.2 (SD 14.4, range 18.0-72.7): 46.9 (15.2, 18.0-71.0) for men and 40.9 (13.9, 18.0-72.7) for women. Mean number of dietary records was 5.6 (SD 3.0), with a minimum of 2 (which represented $7.7 \%(7802 / 101257)$ of the population) and up to 15 records per patient. Table 1 shows the baseline characteristics of the study population according to quarters of sugary drink consumption, after correction for within person and between person variability and variance reduction. Compared with lower consumers of sugary drinks (first quarter), higher consumers (fourth quarter) tended to be younger, more educated, less physically active, and tended to have less family history of cancer, and to have less prevalent cardiometabolic diseases (crude/ unadjusted descriptive comparisons). They also had higher energy, carbohydrate, lipid, and sodium intakes and lower alcohol intake, compared with lower consumers. The proportion of current smokers was slightly higher in the fourth quarter of sugary drinks consumption compared with the first quarter. Median 
daily consumption of sugary drinks was greater in men than in women $(90.3 \mathrm{~mL} v 74.6 \mathrm{~mL}$, respectively; $\mathrm{P}<0.001$, not tabulated). Appendix 3 shows the distribution of total sugary drinks consumption in men and women. Mean number of dietary records was slightly higher in higher consumers (fourth quarter) than in lower consumers (first quarter) of sugary drinks (6.4 v 5.4).

Figure 1 shows that beverages contributing to sugary drinks and artificially sweetened beverages were $100 \%$ fruit juices (45\%), sugary drinks except $100 \%$ fruit juices (36\%), and artificially sweetened beverages (19\%). The Pearson correlation coefficients between sugary drinks and energy intake were 0.23 for overall sugary drinks, 0.17 for sugary drinks except $100 \%$ fruit juices, and 0.17 for $100 \%$ fruit juices. During follow-up (493884 person years, median follow-up time 5.1 years, range 0.003-8.8), 2193 first incident cases of cancer were diagnosed and validated, among which were 693 breast cancers (283 premenopausal, 410 postmenopausal), 291 prostate cancers, and 166 colorectal cancers. Mean age at cancer diagnosis was $58.5 \pm 12.0$.

Main associations between sugary drinks, artificially sweetened beverages, and risk of cancer The proportional hazard assumptions of the Fine and Gray models were met (appendix 5), as well as the assumption of linear dose-response between the intakes of sugary drinks, sugar from sugary drinks, and cancer (appendix 7). Table 2 shows the subdistribution hazard ratios for the associations between sugary drink consumption (continuous and by quarters of consumption) and the risk of cancer. There was a positive association between the consumption of sugary drinks and overall cancer (subdistribution hazard ratio for a $100 \mathrm{~mL} / \mathrm{d}$ increase $1.18,95 \%$ confidence interval 1.10 to $1.27, \mathrm{P}<0.001)$ and breast cancer $(1.22,1.07$ to $1.39, \mathrm{P}=0.004)$ rates. The latter association was more specifically observed for premenopausal $(\mathrm{P}=0.02)$ than for postmenopausal $(\mathrm{P}=0.07)$ breast cancer. However, the median consumption of sugary drinks was lower in menopausal $(88.2 \mathrm{~mL} / \mathrm{d})$ compared with premenopausal $(43.2 \mathrm{~mL} / \mathrm{d})$ women. No association was detected for prostate and colorectal cancers. Appendix 8 shows the models stratified by sex for the association between sugary drinks and colorectal cancer rates. The association between sugary drink consumption and the risk of lung cancer was not significant (subdistribution hazard ratio for a $100 \mathrm{~mL} / \mathrm{d}$ increase $0.61,95 \%$ confidence interval 0.43 to 1.12 , $\mathrm{P}=0.1$, total 101257 , incident cases 88 ) but statistical power was very limited for this cancer location. Results of the association between sugary drinks and the risk of cancer were similar when stratification was performed according to BMI status or weight gain during followup (appendix 9).

An increase in the consumption of $100 \%$ fruit juice was positively associated with overall cancer rate (subdistribution hazard ratio for a $100 \mathrm{~mL} / \mathrm{d}$ increase $1.12,95 \%$ confidence interval 1.03 to $1.23, \mathrm{P}=0.007$; table 2). No interaction was detected between fruit juice intake and smoking status $(\mathrm{P}=0.16)$, nor between sugary drinks overall and smoking status $(\mathrm{P}=0.13)$.

Table 2 shows that an increased consumption of other sugary drinks (that is, all except 100\% fruit juices) was positively associated with overall cancer rate (subdistribution hazard ratio for a $100 \mathrm{~mL} / \mathrm{d}$ increase 1.19 , 95\% confidence interval 1.08 to 1.32 , $\mathrm{P}<0.001)$ and breast cancer $(1.23,1.03$ to 1.48 , $\mathrm{P}=0.02)$, particularly in premenopausal women $(\mathrm{P}=0.005)$.

Artificially sweetened beverages were not associated with the risk of cancer for all cancer sites $(P>0.20$, table 2).

The association between sugar sweetened soda specifically and cancer rate was borderline nonsignificant (subdistribution hazard ratio for a $100 \mathrm{~mL} / \mathrm{d}$ increase 1.03 , 95\% confidence interval 0.99 to 1.23 , $\mathrm{P}=0.06$, total 101257 , incident cases 2193 for overall cancer; $1.10,0.95$ to $1.46, \mathrm{P}=0.07,79724,693$ for breast cancer, data not tabulated), but the consumption was limited (median consumption $=5.8 \mathrm{~mL} / \mathrm{d}$ ).

Appendix 10 shows that an increase of sugar from sugary drinks was positively associated with overall cancer (subdistribution hazard ratio for a $10 \mathrm{~g} / \mathrm{d}$ increase in sugar 1.16, 95\% confidence interval 1.09 to $1.24, \mathrm{P}<0.001)$ and breast cancer $(1.18,1.05$ to 1.33, $\mathrm{P}=0.006)$ rates. Consistently, when the main model was further adjusted for sugar from sugary drinks, the relation between sugary drinks and the risk of overall cancer was not significant $(\mathrm{P}=0.30$; appendix 11). Appendix 10 shows that energy intake from sugary drinks was also associated with cancer rate (subdistribution hazard ratio for an increase of $100 \mathrm{kcal} / \mathrm{d}(1 \mathrm{kcal}=4.18 \mathrm{~kJ}=0.00418 \mathrm{MJ})$ from sugary drinks 1.46 , 95\% confidence interval 1.26 to 1.68 , $\mathrm{P}<0.001$ for overall cancer; $1.54,1.18$ to $2.01, \mathrm{P}=0.001$ for breast cancer).

\section{Sensitivity analyses}

Further adjustments for several indicators of the quality of the diet did not substantially modify the findings, nor did any other sensitivity analyses (appendix 11). Results remained stable when applying a bootstrap approach to account for extra variation (subdistribution hazard ratio for a $100 \mathrm{~mL} / \mathrm{d}$ increase in sugary drink consumption 1.18, 95\% confidence interval 1.02 to 1.34 for overall cancer; $1.23,1.02$ to 1.60 for breast cancer). Appendix 12 shows that causespecific Cox proportional hazard models provided similar results.

\section{Association between the consumption of sugary} drinks and visceral adiposity

Among the 15637 participants for whom bioimpedance data was available, an association between quarters of consumption of sugary drinks and visceral adiposity index was observed (mean 7.43, standard error 0.03 for quarter $4 v 7.34,0.03$ for quarter 1 ; $\mathrm{P}=0.04$ ). No association was observed with artificially sweetened beverages ( $\mathrm{P}=0.07$; appendix 13). 


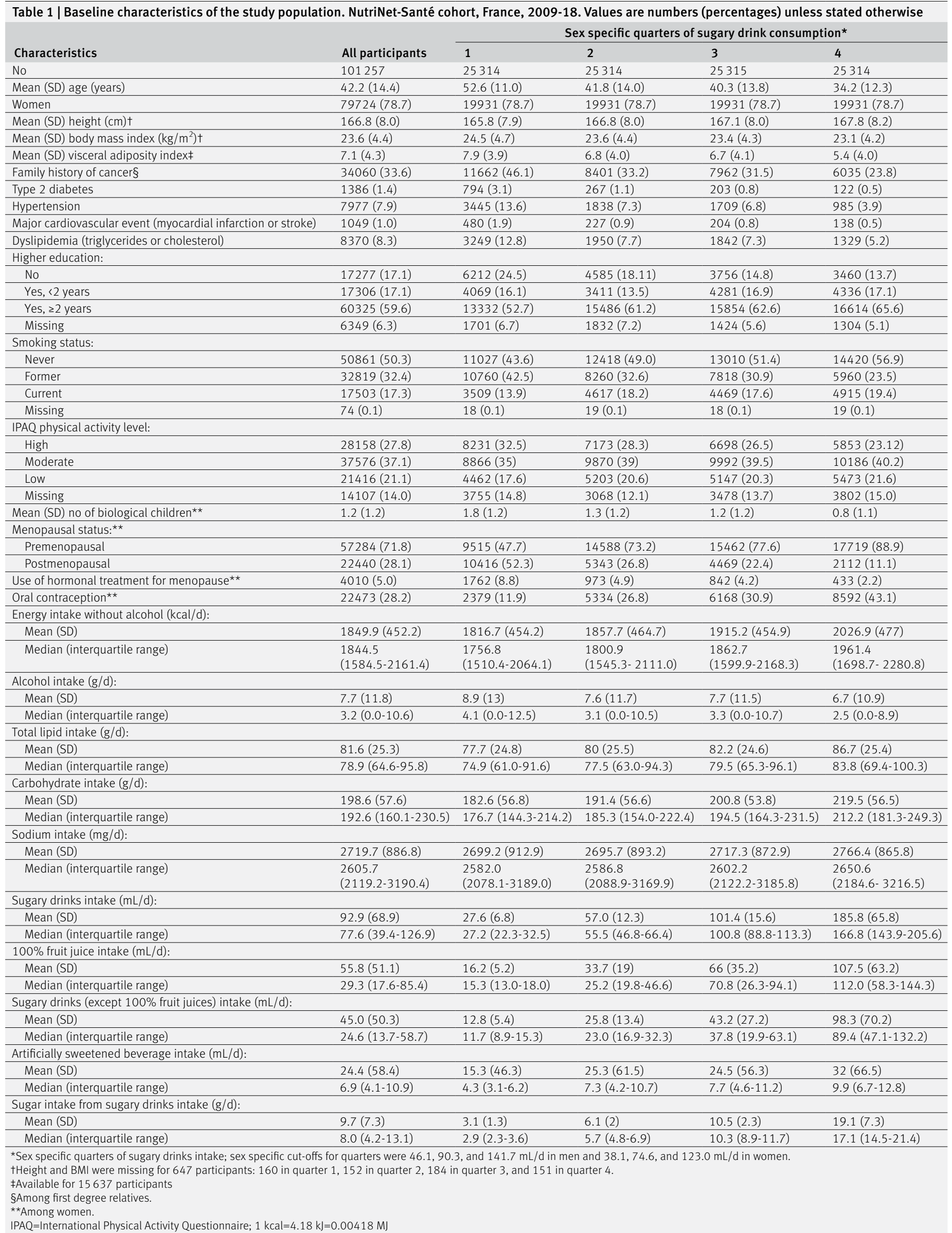




\section{Discussion}

We found that an increase in sugary drink consumption was positively associated with the risk of overall cancer and breast cancer. When the group of sugary drinks was split into $100 \%$ fruit juices and other sugary drinks, the consumption of both beverage types was associated with a higher risk of overall cancer. In contrast, no association was detected between artificially sweetened beverage consumption and the risk of cancer in this study. These results were robust after a wide range of sensitivity analyses.

\section{Comparison with other studies}

Except for pancreatic cancer (non-significant, six prospective studies, 2010), ${ }^{52}$ no meta-analysis was performed by the World Cancer Research Fund/ American Institute for Cancer Research on the association between sugary drinks and the risk of cancer. A meta-analysis showed no link between the consumption of sweetened, ${ }^{29}$ carbonated beverages and the risk of overall cancer and specific locations, unlike our findings. However, this meta-analysis, funded by one of the biggest soda producing companies, did not show the isolated associations in sugary drinks and artificially sweetened beverages, which might have impaired the possibility to detecta potential role of sugar (main driver of the associations in our study). Genkinger and colleagues observed an increased risk of pancreatic cancer associated with sugar sweetened carbonated soft drink consumption in the framework of the Pooling Project (14 cohorts), ${ }^{24}$ and Navarrete-Muñoz and colleagues observed no association in the EPIC cohort. ${ }^{27}$

Data are scarce regarding other cancer sites, notably for breast cancer. The two published prospective cohorts were consistent with our findings; Hodge and colleagues observed an increased risk of breast cancer associated with sugary drinks (Melbourne Collaborative Cohort Study, participants aged 40 and over, 946 cases). ${ }^{22}$ This association was only observed for postmenopausal breast cancer. In contrast with our results, Makarem and colleagues observed no

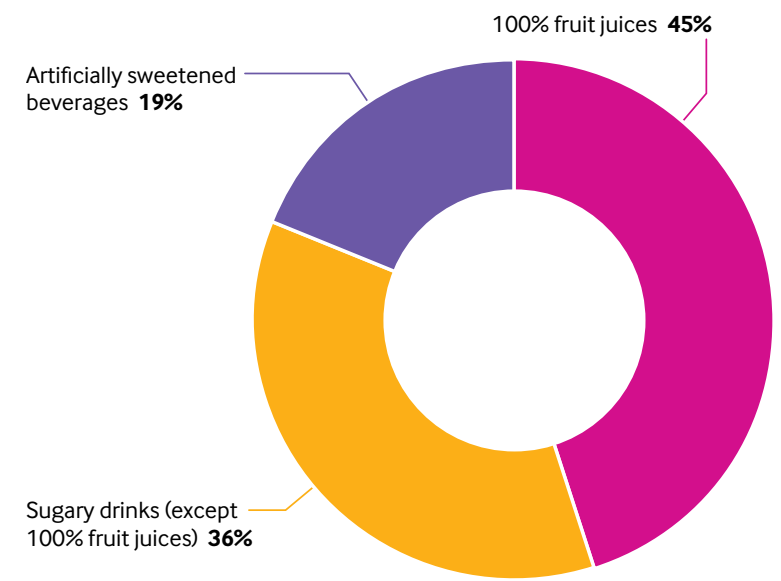

Fig 1 | Contribution of each beverage type to the total of sugary drinks and artificially sweetened beverage consumption association with breast cancer (Framingham Offspring cohort), which might result from a lack of statistical power (124 cases). ${ }^{23}$

In line with our results, a recent meta-analysis observed no association for the risk of colorectal cancer, ${ }^{28}$ even though statistical power was limited for this cancer in our cohort. Results are contrasted regarding prostate cancer in the literature: in line with our findings, no association was observed for sugar sweetened and artificially sweetened sodas in a meta-analysis combining two prospective studies. ${ }^{29}$ Consistently, no association was observed in the Framingham Offspring cohort for sugary drinks, ${ }^{23}$ but an increased risk was observed for $100 \%$ fruit juices; however, statistical power was also limited in this study (157 cases). Sweetened beverage intake was associated with an increased risk of gallbladder cancer in the Swedish Mammography Cohort and Cohort of Swedish Men. ${ }^{25}$ Sugary drinks were associated with increased risk of endometrial cancer in the Swedish Mammography Cohort. ${ }^{26}$ The limited number of cases did not allow us to perform site-specific analyses for these cancer locations in our cohort.

Lastly, and in line with our results, two recent prospective studies observed an increased risk of obesity-related cancers and adiposity-related cancers associated with sugary drink consumption. ${ }^{22} 23$ Furthermore, associations were observed between fruit juice intake and an increased risk of thyroid carcinomas, ${ }^{53}$ and in the EPIC cohort between citrus fruits and juices and increased risk of basal cell and squamous cell carcinomas of the skin. ${ }^{54}$ Of note, despite their overall healthy and natural image in the general population, and some studies suggesting lower health risks compared with sugar sweetened beverages, ${ }^{55-58} 100 \%$ fruit juices generally contain high levels of simple sugar (median=10.3 g/100 mL in this study, sometimes higher than regular soda), ${ }^{59}$ and their glycaemic indexes are higher than that of whole fruits. $^{60}$

\section{Mechanisms}

The association between sugary drinks and the risk of cancer might be partly explained by their effect on overweight and obesity onset, ${ }^{3461}$ since in turn, excess weight is a strong risk factor for mouth, pharynx, larynx, oesophageal (adenocarcinoma), stomach (cardia), pancreatic, gallbladder, liver, colorectal, breast (postmenopause), ovarian, endometrial, prostate (advanced), and kidney cancers. ${ }^{12}$ However, in this study, all analyses testing different adjustments or stratifications related to BMI or weight change (no adjustment for BMI, adjustment for BMI at baseline or as a time dependent variable, adjustment for the percentage of weight change during followup, stratification by baseline BMI status, or by the percentage of weight change during follow-up) provided similar results. These elements suggest that being overweight and weight gain might not be the only drivers of the association between sugary drinks and the risk of cancer. More specifically, it has been 


\begin{tabular}{|c|c|c|c|c|c|c|c|}
\hline \multirow[b]{2}{*}{ Cancer site } & \multicolumn{5}{|c|}{ Sex specific quarters* } & \multicolumn{2}{|c|}{ Continuoust } \\
\hline & 1 & 2 & 3 & 4 & $\begin{array}{l}\text { P value } \\
\text { for trend }\end{array}$ & & $\begin{array}{l}P \text { value } \\
\text { for trend }\end{array}$ \\
\hline \multicolumn{8}{|l|}{ All cancers } \\
\hline Sugary drinks: & & & & & $<0.001$ & & $<0.001$ \\
\hline Participants & 25314 & 25314 & 25315 & 25314 & & 101257 & \\
\hline Incident cases & 743 & 507 & 529 & 414 & & 2193 & \\
\hline SHR $(95 \% \mathrm{Cl})$ & 1 & 1.09 (0.98 to 1.23$)$ & $1.18(1.05$ to 1.33$)$ & $1.30(1.17$ to 1.52$)$ & & $1.18(1.10$ to 1.27$)$ & \\
\hline Sugary drinks except $100 \%$ fruit juices: & & & & & 0.03 & & $<0.001$ \\
\hline Participants & 25314 & 25314 & 25315 & 25314 & & 101257 & \\
\hline Incident cases & 1047 & 330 & 446 & 370 & & 2193 & \\
\hline $\operatorname{sHR}(95 \% \mathrm{Cl})$ & 1 & 0.79 (0.69 to 0.92$)$ & 0.98 (0.97 to 1.10$)$ & $1.06(1.02$ to 1.21$)$ & & $1.19(1.08$ to 1.32$)$ & \\
\hline 100\% fruit juices: & & & & & 0.01 & & 0.007 \\
\hline Participants & 25313 & 25315 & 25315 & 25314 & & 101257 & \\
\hline Incident cases & 863 & 232 & 572 & 526 & & 2193 & \\
\hline $\mathrm{sHR}(95 \% \mathrm{Cl})$ & 1 & $0.96(0.82$ to 1.13$)$ & 1.09 (0.97 to 1.21) & $1.14(1.01$ to 1.29$)$ & & $1.12(1.03$ to 1.23$)$ & \\
\hline Artificially sweetened beverages: & & & & & 0.70 & & 0.60 \\
\hline Participants & 25314 & 25314 & 25319 & 25310 & & 101257 & \\
\hline Incident cases & 1225 & 539 & 140 & 289 & & 2193 & \\
\hline sHR $(95 \% \mathrm{Cl})$ & 1 & $0.94(0.80$ to 1.10$)$ & $0.68(0.53$ to 1.18$)$ & $1.00(0.84$ to 1.19$)$ & & $1.02(0.94$ to 1.10$)$ & \\
\hline \multicolumn{8}{|l|}{ Breast cancer } \\
\hline Sugary drinks: & & & & & 0.01 & & 0.004 \\
\hline Participants & 19931 & 19931 & 19931 & 19931 & & 79724 & \\
\hline Incident cases & 229 & 161 & 166 & 137 & & 693 & \\
\hline $\operatorname{sHR}(95 \% \mathrm{Cl})$ & 1 & 1.09 (0.88 to 1.33$)$ & $1.15(0.94$ to 1.42$)$ & 1.37 (1.08 to 1.73$)$ & & $1.22(1.07$ to 1.39$)$ & \\
\hline Sugary drinks except $100 \%$ fruit juices: & & & & & 0.30 & & 0.02 \\
\hline Participants & 19931 & 19931 & 19931 & 19931 & & 79724 & \\
\hline Incident cases & 317 & 105 & 148 & 123 & & 693 & \\
\hline $\operatorname{sHR}(95 \% \mathrm{Cl})$ & 1 & 0.77 (0.59 to 0.99$)$ & 0.97 (0.79 to 1.19$)$ & $1.10(0.87$ to 1.39$)$ & & $1.23(1.03$ to 1.48$)$ & \\
\hline 100\% fruit juices: & & & & & 0.20 & & 0.10 \\
\hline Participants & 19930 & 19932 & 19931 & 19931 & & 79724 & \\
\hline Incident cases & 259 & 86 & 181 & 167 & & 693 & \\
\hline $\operatorname{sHR}(95 \% \mathrm{Cl})$ & 1 & $0.96(0.73$ to 1.27$)$ & $1.08(0.89$ to 1.32$)$ & $1.13(0.91$ to 1.39$)$ & & $1.15(0.97$ to 1.35$)$ & \\
\hline Artificially sweetened beverages: & & & & & 0.06 & & 0.60 \\
\hline Participants & 19932 & 19929 & 19936 & 19927 & & 79724 & \\
\hline Incident cases & 336 & 205 & 44 & 108 & & 693 & \\
\hline $\operatorname{sHR}(95 \% \mathrm{Cl})$ & 1 & $1.10(0.81$ to 1.50$)$ & $1.41(0.83$ to 2.41$)$ & $1.33(0.98$ to 1.75$)$ & & $0.97(0.86$ to 1.09$)$ & \\
\hline \multicolumn{8}{|l|}{ Premenopausal breast cancer } \\
\hline Sugary drinks: & & & & & 0.04 & & 0.02 \\
\hline Participants & 9335 & 14507 & 15383 & 17676 & & 56901 & \\
\hline Incident cases & 70 & 57 & 80 & 76 & & 283 & \\
\hline $\operatorname{sHR}(95 \% \mathrm{Cl})$ & 1 & $0.95(0.66$ to 1.36$)$ & 1.21 (0.87 to 1.69$)$ & $1.28(1.09$ to 1.83$)$ & & $1.26(1.04$ to 1.51$)$ & \\
\hline Sugary drinks except $100 \%$ fruit juices: & & & & & 0.02 & & 0.005 \\
\hline Participants & 5468 & 17907 & 15808 & 17718 & & 56901 & \\
\hline Incident cases & 69 & 69 & 67 & 78 & & 283 & \\
\hline $\operatorname{sHR}(95 \% \mathrm{Cl})$ & 1 & $0.61(0.41$ to 0.99$)$ & $0.84(0.59$ to 1.20$)$ & $1.68(1.45$ to 1.74$)$ & & $1.37(1.10$ to 1.70$)$ & \\
\hline $100 \%$ fruit juices: & & & & & 0.90 & & 0.50 \\
\hline Participants & 7554 & 18870 & 14285 & 16192 & & 56901 & \\
\hline Incident cases & 60 & 73 & 74 & 76 & & 283 & \\
\hline $\operatorname{sHR}(95 \% \mathrm{Cl})$ & 1 & 0.95 (0.63 to 1.42$)$ & $1.06(0.73$ to 1.54$)$ & $0.98(0.67$ to 1.43$)$ & & $1.10(0.85$ to 1.41$)$ & \\
\hline Artificially sweetened beverages: & & & & & 0.50 & & 0.60 \\
\hline Participants & 1243 & 17936 & 19904 & 17818 & & 56901 & \\
\hline Incident cases & 8 & 180 & 43 & 52 & & 283 & \\
\hline $\operatorname{sHR}(95 \% \mathrm{Cl})$ & 1 & 1.11 (0.49 to 2.49$)$ & $1.29(0.50$ to 3.31$)$ & $1.23(0.52$ to 2.93$)$ & & $0.95(0.81$ to 1.13$)$ & \\
\hline \multicolumn{8}{|l|}{ Postmenopausal breast cancer } \\
\hline Sugary drinks: & & & & & 0.04 & & 0.07 \\
\hline Participants & 11664 & 6126 & 5275 & 2717 & & 25782 & \\
\hline Incident cases & 159 & 104 & 86 & 61 & & 410 & \\
\hline $\operatorname{sHR}(95 \% \mathrm{Cl})$ & 1 & 1.17 (0.91 to 1.50$)$ & $1.08(0.83$ to 1.42$)$ & 1.44 (1.05 to 1.99$)$ & & $1.19(0.98$ to 1.44$)$ & \\
\hline Sugary drinks except $100 \%$ fruit juices: & & & & & 0.90 & & 0.60 \\
\hline Participants & 16043 & 2239 & 4866 & 2634 & & 25782 & \\
\hline Incident cases & 248 & 36 & 81 & 45 & & 410 & \\
\hline $\operatorname{sHR}(95 \% \mathrm{Cl})$ & 1 & 0.95 (0.67 to 1.35$)$ & $1.03(0.79$ to 1.34$)$ & $0.99(0.72$ to 1.39$)$ & & $1.08(0.79$ to 1.47$)$ & \\
\hline $100 \%$ fruit juices: & & & & & 0.10 & & 0.10 \\
\hline Participants & 13524 & 1436 & 6426 & 4396 & & 25782 & \\
\hline Incident cases & 199 & 13 & 107 & 91 & & 410 & \\
\hline $\operatorname{sHR}(95 \% \mathrm{Cl})$ & 1 & $0.81(0.45$ to 1.45$)$ & $1.07(0.84$ to 1.36$)$ & $1.24(0.95$ to 1.61$)$ & & 1.19 (0.96 to 1.48$)$ & \\
\hline
\end{tabular}




\begin{tabular}{|c|c|c|c|c|c|c|c|}
\hline \multicolumn{8}{|l|}{ Table 2 | Continued } \\
\hline \multirow[b]{2}{*}{ Cancer site } & \multicolumn{5}{|c|}{ Sex specific quarters* } & \multicolumn{2}{|c|}{ Continuoust } \\
\hline & 1 & 2 & 3 & 4 & $\begin{array}{l}\text { P value } \\
\text { for trend }\end{array}$ & & $\begin{array}{l}\text { P value } \\
\text { for trend }\end{array}$ \\
\hline Artificially sweetened beverages: & & & & & 0.90 & & 0.90 \\
\hline Participants & 19686 & 3601 & 32 & 2463 & & 25782 & \\
\hline Incident cases & 328 & 25 & 1 & 56 & & 410 & \\
\hline $\operatorname{sHR}(95 \% \mathrm{Cl})$ & 1 & 1.34 (0.99 to 2.10$)$ & 1.80 (0.96 to 2.95$)$ & 1.10 (0.55 to 2.12$)$ & & $1.01(0.86$ to 1.18$)$ & \\
\hline \multicolumn{8}{|l|}{ Colorectal cancer } \\
\hline Sugary drinks: & & & & & 0.50 & & 0.50 \\
\hline Participants & 25314 & 25314 & 25315 & 25314 & & 101257 & \\
\hline Incident cases & 89 & 20 & 39 & 18 & & 166 & \\
\hline $\operatorname{sHR}(95 \% \mathrm{Cl})$ & 1 & 1.07 (0.71 to 1.60$)$ & $1.21(0.80$ to 1.84$)$ & 1.07 (0.63 to 1.80$)$ & & $1.10(0.84$ to 1.46$)$ & \\
\hline Sugary drinks except $100 \%$ fruit juices: & & & & & 0.40 & & 0.70 \\
\hline Participants & 25314 & 25314 & 25315 & 25314 & & 101257 & \\
\hline Incident cases & 89 & 20 & 39 & 18 & & 166 & \\
\hline sHR $(95 \% \mathrm{Cl})$ & 1 & 0.97 (0.58 to 1.59) & 1.37 (0.93 to 2.02$)$ & 1.01 (0.59 to 1.71$)$ & & $1.11(0.72$ to 1.71$)$ & \\
\hline $100 \%$ fruit juices: & & & & & 0.60 & & 0.80 \\
\hline Participants & 25313 & 25315 & 25315 & 25314 & & 101257 & \\
\hline Incident cases & 80 & 10 & 38 & 38 & & 166 & \\
\hline $\operatorname{sHR}(95 \% \mathrm{Cl})$ & 1 & $0.81(0.40$ to 1.62$)$ & $0.90(0.61$ to 1.33$)$ & 1.19 (0.78 to 1.82$)$ & & $1.05(0.75$ to 1.46$)$ & \\
\hline Artificially sweetened beverages: & & & & & 0.40 & & 0.60 \\
\hline Participants & 25314 & 25314 & 25319 & 25310 & & 101257 & \\
\hline Incident cases & 119 & 29 & 4 & 14 & & 166 & \\
\hline $\operatorname{sHR}(95 \% \mathrm{Cl})$ & 1 & $0.65(0.37$ to 1.14$)$ & $0.84(0.21$ to 3.42$)$ & $0.80(0.44$ to 1.46$)$ & & $1.02(0.94$ to 1.10$)$ & \\
\hline \multicolumn{8}{|l|}{ Prostate cancer } \\
\hline Sugary drinks: & & & & & 0.09 & & 0.30 \\
\hline Participants & 5383 & 5383 & 5384 & 5383 & & 21533 & \\
\hline Incident cases & 107 & 69 & 69 & 46 & & 291 & \\
\hline $\operatorname{sHR}(95 \% \mathrm{Cl})$ & 1 & $1.17(0.86$ to 1.59$)$ & $1.16(0.85$ to 1.59$)$ & $1.39(0.96$ to 2.02$)$ & & $1.10(0.92$ to 1.31$)$ & \\
\hline Sugary drinks except $100 \%$ fruit juices: & & & & & 0.40 & & 0.10 \\
\hline Participants & 5383 & 5383 & 5384 & 5383 & & 21533 & \\
\hline Incident cases & 164 & 34 & 51 & 42 & & 291 & \\
\hline $\operatorname{sHR}(95 \% \mathrm{Cl})$ & 1 & $0.91(0.62$ to 1.35$)$ & $1.00(0.72$ to 1.39$)$ & $1.19(0.83$ to 1.72$)$ & & $1.24(0.95$ to 1.62$)$ & \\
\hline $100 \%$ fruit juices: & & & & & 0.80 & & 0.80 \\
\hline Participants & 5383 & 5383 & 5384 & 5383 & & 21533 & \\
\hline Incident cases & 135 & 15 & 75 & 66 & & 291 & \\
\hline $\operatorname{sHR}(95 \% \mathrm{Cl})$ & 1 & 0.84 (0.46 to 1.52$)$ & $0.99(0.74$ to 1.32$)$ & $1.04(0.76$ to 1.42$)$ & & $0.97(0.79$ to 1.2$)$ & \\
\hline Artificially sweetened beverages: & & & & & 0.10 & & 0.20 \\
\hline Participants & 5382 & 5385 & 5383 & 5383 & & 21533 & \\
\hline Incident cases & 216 & 62 & 0 & 13 & & 291 & \\
\hline $\operatorname{sHR}(95 \% \mathrm{Cl})$ & 1 & $1.10(0.81$ to 1.50$)$ & 1.41 (0.83 to 2.41$)$ & $1.33(1.01$ to 1.75$)$ & & $0.57(0.24$ to 1.34$)$ & \\
\hline $\begin{array}{l}\text { *Sex specific cut-offs for quarters of sugary d } \\
\text { juices intake were } 19.9,34.9 \text {, and } 97.8 \mathrm{~mL} / \mathrm{c} \\
\text { and } 65.5 \mathrm{~mL} / \mathrm{d} \text { in men and } 13.6,24.1 \text {, and } 5 \\
11.6 \mathrm{~mL} / \mathrm{d} \text { in women. } \\
\text { tFor sugary drinks (all), sugary drinks except } \\
\text { subdistribution hazard ratios are given for an }\end{array}$ & $\begin{array}{l}\mathrm{ss} \text { intake } \\
\mathrm{men} \text { and } \\
\mathrm{mL} / \mathrm{d} \text { in }\end{array}$ & $\begin{array}{l}38.1,74.6 \text {, and } 123.0 \\
0,26.2 \text {, and } 81.9 \mathrm{~mL} / \mathrm{d} \\
\text { nen. Sex specific cut-offs }\end{array}$ & $\begin{array}{l}\mathrm{L} / \mathrm{d} \text { in women and } 46.1 \text {, } \\
\text { women. Sex specific cut } \\
\text { or quarters of artificially }\end{array}$ & $\begin{array}{l}0.3 \text {, and } 141.7 \mathrm{~mL} / \mathrm{d} \text { in } \\
\text { ffs for quarters of sugary } \\
\text { eetened beverages intak }\end{array}$ & $\begin{array}{l}\text { Sex spec } \\
\text { nks excep } \\
\text { ere } 2.7,4\end{array}$ & $\begin{array}{l}\text { cut-offs for quarters of } 10 \\
0 \% \% \text { fruit juices intake wer } \\
\text { and } 7.9 \mathrm{~mL} / \mathrm{d} \text { in men and }\end{array}$ & $\begin{array}{l}0 \% \text { fruit } \\
\text { e } 14.0,27.1 \\
4.6,7.7 \text {, an } \\
\text { everages, }\end{array}$ \\
\hline
\end{tabular}

suggested that sugary drinks might promote gains in visceral adiposity independently of body weight; this was the case in the prospective Framingham Third Generation Cohort. ${ }^{62}$ Two randomised trials also support the hypothesis that sugary drinks promote visceral fat deposits. ${ }^{6364}$ Visceral adiposity might promote tumorigenesis through alterations in adipokine secretion and cell signalling pathways. ${ }^{65} \mathrm{In}$ our study, sugary drinks consumption was associated with increased visceral adiposity, suggesting that it might have played a role in the association with cancer, independently of body weight.

Another pathway could relate to the high glycaemic index or glycaemic load of sugary drinks. Glycaemic index is associated with hyperinsulinemia and type 2 diabetes, ${ }^{66}$ both potentially involved in breast carcinogenesis. $^{67}$ Rapidly absorbed carbohydrates were previously associated with the risk of postmenopausal breast cancer in women who were overweight and women with large waist circumference in the EPIC-France (E3N) cohort. $^{68}$ Also, glycaemic load is associated with increased proinflammatory markers, such as $\mathrm{C}$ reactive protein, ${ }^{69}$ and systemic inflammation is suggested to increase the risk of several cancers, including breast cancer. ${ }^{70}$ Furthermore, two meta-analyses of prospective cohort studies suggest that high dietary glycaemic index is associated with a noticeably increased risk of breast cancer. ${ }^{13}{ }^{14}$ Also, glycaemic index is associated with diabetes-related carcinomas (liver, pancreas, endometrium, colorectal, breast, bladder, and reduced risk of prostate cancer). ${ }^{16} 71$ Advanced glycation end products present in several sugary drinks were also suggested to impair endothelial function in patients with and without diabetes. ${ }^{72}$ In this study, daily intake of sugar from sugary drinks was positively associated with overall cancer and breast cancer. Adjustment for sugar from sugary drinks cancelled the association 
between sugary drinks and cancer. These results suggest that the relation observed between sugary drinks and the risk of cancer was strongly driven by the sugar content. Of note, even sugary drinks with lower sugar content were associated with cancer in this study, probably because they were consumed in higher amounts than sugary drinks with higher sugar content. In contrast, water and unsweetened tea and coffee were not associated with cancer in this study. In many countries, water is the only beverage public health authorities recommend drinking. ${ }^{7374}$

Although sugar appears as a strong driver of the association, other chemical compounds might also play a role, such as 4-methylimidazole, an additive in drinks that contain caramel colouring (eg, sodas) or pesticides that might be associated with increased risk of cancer and could be present in fruit juice. ${ }^{19} 182075$ Regarding $100 \%$ fruit juices, one other explanation could be that fruit juice antioxidants might interact with tobacco smoke to potentialise carcinogenesis. ${ }^{51}$ However, the absence of an interaction between fruit juice consumption and smoking status does not support this hypothesis.

Null results observed in this study regarding the association between artificially sweetened beverages and the risk of cancer does not support the hypothesis of an adverse effect of artificial sweeteners. However, caution is needed in interpreting this finding because statistical power might have been limited to investigate this association owing to the relatively low level of consumption in this population study (median=6.9 mL/d). Some experimental studies suggest a possible carcinogenic effect for some artificial sweeteners, but this point is debated. ${ }^{76-78}$ In order to evaluate accurately these associations in humans, it will be necessary to distinguish the different types of artificial sweeteners (eg, aspartame, sucralose, acesulfam $\mathrm{K}$ ), and also to take into account all dietary sources for these additives (eg, yogurts, candies) and not only artificially sweetened beverages.

\section{Strengths and limitations of this study}

Strengths of our study include its large sample size and its detailed and up to date assessment of consumed beverage types. Some limitations include generalisability of the findings: by definition, recruited participants in volunteer based cohorts are not representative of the general population of the country. Since the participants of the NutriNet-Santé cohort were more often women, with health conscious behaviours and higher socioprofessional and educational levels than the general French population, ${ }^{79}$ this might have resulted in a lower cancer incidence compared with national estimates (age and sex standardised incidence rate per 100000 persons per year: 620 cases in this study $v 972$ cases in France $)^{8}$ and a lower exposure to sugary drinks overall, thus a lower contrast between extreme categories. Indeed, although the comparison is not straightforward owing to differences in beverage type definitions, mean intake of sugary drinks and artificially sweetened beverages represented 117.3
$\mathrm{mL} / \mathrm{d}$ in our study, versus approximately $270.0 \mathrm{~mL} / \mathrm{dfor}$ non-alcoholic refreshing drinks in the recent French national INCA3 survey. ${ }^{80}$ Although overestimation cannot be totally excluded, these points rather tended to underestimate the strength of the associations in this study compared with the real associations in the general French adult population.

Secondly, even if cancer cases where identified by multiple sources, exhaustive identification cannot be guaranteed.

Thirdly, the number of cases was limited for some cancer locations, thus reducing the statistical power, which could have impaired our ability to detect associations, for instance for colorectal carcinomas, and for lung cancer (probably owing to a lower proportion of smokers in the cohort compared with the general population).

Fourthly, lower consumers were older than high consumers of sugary drinks in this study, and as such, they also had a lower educational level, higher alcohol intake, and more cardiometabolic disorders (all expected associations with older age). However, these associations could not explain our aetiological findings since, on the contrary, the potential confounding bias would have acted towards an underestimation of the strength of the associations in our study, compared with the reality. Indeed, lower consumers of sugary drinks were at higher risk of cancer regarding these characteristics, whereas after adjustment, we observed that higher sugary drink consumers had a higher risk of cancer.

Fifthly, measurement bias owing to misreporting cannot be ruled out, especially since exposures, covariates, and outcomes were based on self report measures. Notably, diet is one of the most complex exposures to assess and its evaluation is challenging. ${ }^{81}$ This challenge is not specific to our study but rather shared by all major epidemiological studies conducted worldwide in this field. ${ }^{82} 83$ The NutriNet-Santé cohort benefits from a detailed dietary assessment measured by repeated and validated (versus biomarkers) ${ }^{84} 85$ 24 hour dietary records. In addition, the prospective design of the cohort guaranteed that potential measurement errors in dietary exposure (eg, amounts of sugary drinks consumed) were non-differential regarding the outcome. They could have led to a nondifferential classification bias (identically in future cases and other participants), most probably leading to an underestimation of the observed associations, although overestimation cannot be entirely ruled out. In nutritional epidemiology, a compromise has to be found between a high number of records per patient (better accuracy of the data but higher selection bias towards a very compliant population) or conversely, a smaller number of dietary records (lower degree of precision but lower selection bias compared with the general population). There is no perfect answer, thus we tested and presented the different possibilities, which showed consistent results. We also applied the variance reduction method proposed by the US National Cancer Institute to all dietary exposure variables to account for within person and between 
person variability, ${ }^{44}$ which is adapted for occasionallyconsumed foods and beverages.

Next, mean age at baseline was 42.2 but participants were followed up to nine years, the cohort included a large range of age (up to 72.7), and mean age at diagnosis was 58.5. Furthermore, the cohort was launched in 2009 and follow-up lasted until early 2018, thus, including participant with up to nine years of follow-up. This allowed us to study midterm associations between sugary drink consumption and cancer. Besides, as is usually the case in nutritional epidemiology, the assumption is made that the measured exposure at baseline (especially since we averaged a two year period of exposure) actually reflects more generally the usual eating habits of the individual during adulthood, including several years before his or her entry into the cohort. Nevertheless, since some carcinogenic processes can take several decades, it will be important in the future to reassess the associations between sugary drinks and cancer in the cohort, to investigate longer-term effects. This will be one of the objective for the next 10 years.

Finally, this is an observational study, thus causality of the observed associations cannot be established and residual confounding cannot be entirely ruled out. For instance, although BMI (used for adjustment in this study) is considered as a good indicator of adiposity, ${ }^{86}$ it would have been useful to test adjustment for more precise indicators such as waist circumference or visceral adiposity, but these data were not available for the whole cohort. Moreover, glycaemic index or glycaemic load were not available in this study and should be integrated in future investigations in order to better elucidate the mechanistic pathway involved in the associations between sugary drinks and cancer. However, a wide range of confounding factors were included in the analyses and many sensitivity analyses were performed (testing further adjustments or stratifications, or both). None substantially modified the findings, which remained statistically significant and stable. Besides, mechanistic data support the epidemiological findings observed here, as detailed above. In the future, if these results are replicated in other large cohort prospective studies and if causality is established, it will be interesting to conduct a substitution analysis and simulation studies to model the decrease in cancer incidence associated with the replacement of sugary drink consumption by water, for instance.

\section{Conclusions}

In a context where the World Health Organization is questioning the level of evidence of the scientific data supporting the implementation of a tax on sugary drinks, the results of this observational study based on a large prospective cohort suggest that a higher consumption of sugary drinks is associated with the risk of overall cancer and breast cancer. Of note, $100 \%$ fruit juices were also associated with the risk of overall cancer in this study. If these results are replicated in further large-scale prospective studies and supported by mechanistic experimental data, and given the large consumption of sugary drinks in Western countries, these beverages would represent a modifiable risk factor for cancer prevention, beyond their well established impact on cardiometabolic health. These data support the relevance of existing nutritional recommendations to limit sugary drink consumption, including $100 \%$ fruit juice, ${ }^{12} 87$ as well as policy actions, such as taxation and marketing restrictions targeting sugary drinks, which might potentially contribute to the reduction of cancer incidence. ${ }^{88} 89$

We thank all the volunteers of the NutriNet-Santé cohort. We also thank Younes Esseddik (IT manager); Frédéric Coffinieres, Thi Hong Van Duong, Paul Flanzy, Régis Gatibelza, Jagatjit Mohinder, and Maithyly Sivapalan (computer scientists); Cédric Agaesse (dietitian); Julien Allègre, Nathalie Arnault, Laurent Bourhis, Véronique Gourlet, and Fabien Szabo de Edelenyi (data managers or biostatisticians); and Rolland Andrianasolo and Fatoumata Diallo (physicians) for their technical contribution to the NutriNet-Santé study.

Contributors: EC, BS, and MT designed the study. SH, PG, MT, CJ, and EKG conducted the study. EC performed the statistical analysis. MT and BS supervised the statistical analysis. EC drafted the manuscript. BS and MT supervised the writing. All authors contributed to the data interpretation and revised each draft for important intellectual content. All authors read and approved the final manuscript. All authors had full access to the data in the study and can take responsibility for the integrity of the data and the accuracy of the data analysis. MT is the guarantor. The corresponding author (BS) attests that all listed authors meet authorship criteria and that no others meeting the criteria have been omitted.

Funding: The NutriNet-Santé study was supported by the following public institutions: Ministère de la Santé, Santé Publique France, Institut National de la Santé et de la Recherche Médicale (INSERM), Institut National de la Recherche Agronomique (INRA), Conservatoire National des Arts et Métiers (CNAM), and Université Paris 13. BS was funded by the French National Cancer Institute (grant number INCa_8085) and the Fondation de France. Researchers were independent from funders. Funders had no role in the study design, the collection, analysis, and interpretation of data, the writing of the report, and the decision to submit the article for publication.

Competing interests: All authors have completed the ICMJE uniform disclosure form at www.icmje.org/coi_disclosure.pdf and declare: no support from any organisation for the submitted work; no financial relationships with any organisations that might have an interest in the submitted work in the previous three years; no other relationships or activities that could appear to have influenced the submitted work.

Ethical approval: The study is conducted according to the Declaration of Helsinki guidelines and was approved by the Institutional Review Board of the French Institute for Health and Medical Research (IRB Inserm n0000388FWA00005831), the Commission Nationale de l'Informatique et des Libertés (CNIL n908450/n909216/ $\left.n^{\circ} 1460707\right)$, and the Consultation Committee for the Protection of Participants in Biomedical Research (C09-42 on 5 May 2010). Electronic informed consent is obtained from each participant. Data sharing: No additional data are available.

The guarantor (MT) affirms that the manuscript is an honest, accurate, and transparent account of the study being reported; that no important aspects of the study have been omitted; and that any discrepancies from the study as planned have been explained.

This is an Open Access article distributed in accordance with the Creative Commons Attribution Non Commercial (CC BY-NC 4.0) license, which permits others to distribute, remix, adapt, build upon this work non-commercially, and license their derivative works on different terms, provided the original work is properly cited and the use is noncommercial. See: http://creativecommons.org/licenses/by-nc/4.0/.

1 GBD 2016 Risk Factors Collaborators. Global, regional, and national comparative risk assessment of 84 behavioural, environmental and occupational, and metabolic risks or clusters of risks, 19902016: a systematic analysis for the Global Burden of Disease Study 2016. Lancet 2017;390:1345-1422. doi:10.1016/S01406736(17)32366-8

2 Mozaffarian D. Dietary and Policy Priorities for Cardiovascular Disease, Diabetes, and Obesity: A Comprehensive Review. Circulation 2016;133:187-225. doi:10.1161/ CIRCULATIONAHA.115.018585 
3 Te Morenga L, Mallard S, Mann J. Dietary sugars and body weight: systematic review and meta-analyses of randomised controlled trials and cohort studies. BM/ 2012;346:e7492. doi:10.1136/bmi.e7492

4 Malik VS, Pan A, Willett WC, Hu FB. Sugar-sweetened beverages and weight gain in children and adults: a systematic review and meta-analysis. Am J Clin Nutr 2013;98:1084-102. doi:10.3945/ ajcn.113.058362

5 Imamura F, O'Connor L, Ye Z, et al. Consumption of sugar sweetened beverages, artificially sweetened beverages, and fruit juice and incidence of type 2 diabetes: systematic review, meta-analysis, and estimation of population attributable fraction. BMJ 2015;351:h3576. doi:10.1136/bmj.h3576

6 Schwingshackl L, Schwedhelm C, Hoffmann G, et al. Food Groups and Risk of Hypertension: A Systematic Review and Dose-Response Meta-Analysis of Prospective Studies. Adv Nutr 2017;8:793-803. doi:10.3945/an 117.017178

7 Micha R, Peñalvo JL, Cudhea F, Imamura F, Rehm CD, Mozaffarian D. Association Between Dietary Factors and Mortality From Heart Disease, Stroke, and Type 2 Diabetes in the United States. JAMA 2017;317:912-24. doi:10.1001/jama.2017.0947

8 Singh GM, Micha R, Khatibzadeh S, Lim S, Ezzati M, Mozaffarian DGlobal Burden of Diseases Nutrition and Chronic Diseases Expert Group (NutriCoDE). Estimated Global, Regional, and National Disease Burdens Related to Sugar-Sweetened Beverage Consumption in 2010. Circulation 2015;132:639-66. doi:10.1161/ CIRCULATIONAHA.114.010636

$9 \operatorname{Kim}$ Y, Je Y. Prospective association of sugar-sweetened and artificially sweetened beverage intake with risk of hypertension. Arch Cardiovasc Dis 2016;109:242-53. doi:10.1016/j. acvd.2015.10.005

10 Ruanpeng D, Thongprayoon C, Cheungpasitporn W, Harindhanavudhi T. Sugar and artificially sweetened beverages linked to obesity: a systematic review and meta-analysis. QJM 2017;110:513-20. doi:10.1093/qjmed/hcx068

11 Suez J, Korem T, Zeevi D, et al. Artificial sweeteners induce glucose intolerance by altering the gut microbiota. Nature 2014;514:181-6. doi:10.1038/nature 13793

12 World Cancer Research Fund/American Institute for Cancer Research. Diet, Nutrition, Physical Activity and Cancer: a Global Perspective. Continuous Update Project Expert Report 2018. https://www.wcrf. $\mathrm{org} / \mathrm{sites} /$ default/files/Summary-third-expert-report.pdf

13 Dong J-Y, Qin L-Q. Dietary glycemic index, glycemic load, and risk of breast cancer: meta-analysis of prospective cohort studies. Breast Cancer Res Treat 2011;126:287-94. doi:10.1007/s10549-0111343-3

14 Schlesinger S, Chan DSM, Vingeliene S, et al. Carbohydrates, glycemic index, glycemic load, and breast cancer risk: a systematic review and dose-response meta-analysis of prospective studies. Nutr Rev 2017;75:420-41. doi:10.1093/nutrit/nux010

15 Laguna JC, Alegret M, Roglans N. Simple sugar intake and hepatocellular carcinoma: epidemiological and mechanistic insight. Nutrients 2014;6:5933-54. doi:10.3390/nu6125933

16 Choi Y, Giovannucci E, Lee JE. Glycaemic index and glycaemic load in relation to risk of diabetes-related cancers: a meta-analysis. $\mathrm{Br} /$ Nutr 2012;108:1934-47. doi:10.1017/S0007114512003984

17 Smith TJS, Wolfson JA, Jiao D, et al. Caramel Color in Soft Drinks and Exposure to 4-Methylimidazole: A Quantitative Risk Assessment. 2015 https://www.ncbi.nlm.nih.gov/pmc/articles/PMC4333292/

18 International Agency for Research on Cancer. 4-Methylimidazole. In IARC Monographs on the Evaluation of Carcinogenic Risks to Humans. vol. 101: Some Chemicals Present in Industrial and Consumer Products, Food and Drinking-water, pp. 447-459. 2013 https://monographs.iarc.fr/ENG/Monographs/vol101/mono101015.pdf

19 Nardin T, Barnaba C, Abballe F, Trenti G, Malacarne M, Larcher R. Fast analysis of quaternary ammonium pesticides in food and beverages using cation-exchange chromatography coupled with isotope-dilution high-resolution mass spectrometry. J Sep Sci 2017;40:3928-37. doi:10.1002/jssc.201700579

20 Albero B, Sánchez-Brunete C, Tadeo JL. Determination of organophosphorus pesticides in fruit juices by matrix solidphase dispersion and gas chromatography. J Agric Food Chem 2003:51:6915-21. doi:10.1021/if030414m

21 European Food Safety Authority. Scientific Opinion on the re-evaluation of aspartame (E 951) as a food additive. EFSA | 2013;11:3496.

22 Hodge AM, Bassett JK, Milne RL, English DR, Giles GG. Consumption of sugar-sweetened and artificially sweetened soft drinks and risk of obesity-related cancers. Public Health Nutr 2018;21:1618-26. doi:10.1017/S1368980017002555

23 Makarem N, Bandera EV, Lin Y, Jacques P, Hayes RB, Parekh N. Consumption of Sugars, Sugary Foods and Sugary Beverages in Relation to Adiposity-Related Cancer Risk in the Framingham Offspring Cohort. Cancer Prev Res (Phila) 2013;2018:19. doi:10.1158/1940-6207.CAPR-17-0218
24 Genkinger JM, Li R, Spiegelman D, et al. Coffee, tea, and sugar sweetened carbonated soft drink intake and pancreatic cancer risk: a pooled analysis of 14 cohort studies. Cancer Epidemiol Biomarkers Prev 2012;21:305-18. doi:10.1158/1055-9965.EPI-11-0945-T

25 Larsson SC, Giovannucci EL, Wolk A. Sweetened Beverage Consumption and Risk of Biliary Tract and Gallbladder Cancer in a Prospective Study. J Natl Cancer Inst 2016;108:djw125. doi:10.1093/jnci/djw125

26 Friberg E, Wallin A, Wolk A. Sucrose, high-sugar foods, and risk of endometrial cancer--a population-based cohort study. Cancer Epidemiol Biomarkers Prev 2011;20:1831-7. doi:10.1158/10559965.EPI-11-0402

27 Navarrete-Muñoz EM, Wark PA, Romaguera D, et al. Sweet-beverage consumption and risk of pancreatic cancer in the European Prospective Investigation into Cancer and Nutrition (EPIC). Am J Clin Nutr 2016;104:760-8. doi:10.3945/ajcn.116.130963

28 Schwingshackl L, Schwedhelm C, Hoffmann G, et al. Food groups and risk of colorectal cancer. Int J Cancer 2018;142:1748-58. doi:10.1002/ijc.31198

29 Boyle P, Koechlin A, Autier P. Sweetened carbonated beverage consumption and cancer risk: meta-analysis and review. Eur J Cancer Prev 2014;23:481-90. doi:10.1097/CEJ.0000000000000015

30 Hercberg S, Castetbon K, Czernichow S, et al. The Nutrinet-Santé Study: a web-based prospective study on the relationship between nutrition and health and determinants of dietary patterns and nutritional status. BMC Public Health 2010;10:242. doi:10.1186/1471-2458-10-242

31 Vergnaud A-C, Touvier M, Méjean C, et al. Agreement between webbased and paper versions of a socio-demographic questionnaire in the NutriNet-Santé study. Int J Public Health 2011;56:407-17. doi:10.1007/s00038-011-0257-5

32 Lassale C, Péneau S, Touvier M, et al. Validity of Web-Based SelfReported Weight and Height: Results of the Nutrinet-Santé Study. J Med Internet Res. 2013 https://www.ncbi.nlm.nih.gov/pmc/articles/ PMC3742400/

33 Touvier M, Méjean C, Kesse-Guyot E, et al. Comparison between web-based and paper versions of a self-administered anthropometric questionnaire. EurJ Epidemiol 2010;25:287-96. doi:10.1007/ s10654-010-9433-9

34 Touvier M, Kesse-Guyot E, Méjean C, et al. Comparison between an interactive web-based self-administered $24 \mathrm{~h}$ dietary record and an interview by a dietitian for large-scale epidemiological studies. $\mathrm{Br}$ J Nutr 2011:105:1055-64 doi:10.1017/S0007114510004617

35 Lassale C, Castetbon K, Laporte F, et al. Validation of a Web-based, self-administered, non-consecutive-day dietary record tool against urinary biomarkers. Br J Nutr 2015;113:953-62. doi:10.1017/ S0007114515000057

36 Lassale C, Castetbon K, Laporte F, et al. Correlations between Fruit, Vegetables, Fish, Vitamins, and Fatty Acids Estimated by Web-Based Nonconsecutive Dietary Records and Respective Biomarkers of Nutritional Status. J Acad Nutr Diet 2016;116:427-38. doi:10.1016/j.jand.2015.09.017

37 Craig CL, Marshall AL, Sjöström M, et al. International physical activity questionnaire: 12 -country reliability and validity. Med Sci Sports Exerc 2003;35:1381-95. doi:10.1249/01. MSS.0000078924.61453.FB

38 Andreeva VA, Galan P, Julia C, Castetbon K, Kesse-Guyot E, Hercberg S. Assessment of response consistency and respective participant profiles in the Internet-based NutriNet-Santé Cohort. Am J Epidemiol 2014:179:910-6. doi:10.1093/aje/kwt431

39 Lassale C, Castetbon K, Laporte F, et al. Correlations between Fruit, Vegetables, Fish, Vitamins, and Fatty Acids Estimated by Web-Based Nonconsecutive Dietary Records and Respective Biomarkers of Nutritional Status. http://spiral.imperial.ac.uk/ handle/10044/1/39786

40 Black AE. Critical evaluation of energy intake using the Goldbers cut-off for energy intake:basal metabolic rate. A practical guide to its calculation, use and limitations. Int J Obes Relat Metab Disord 2000;24:1119-30. doi:10.1038/sj.ijo.0801376

41 Pietrobelli A, Rubiano F, St-Onge M-P, Heymsfield SB. New bioimpedance analysis system: improved phenotyping with wholebody analysis. Eur J Clin Nutr 2004;58:1479-84. doi:10.1038/ sj.ejcn.1601993

42 Rubiano F, Nuñez C, Gallagher D, Heymsfield SB. Comparison of leg-to-leg bioimpedance (BIA) system with dual energy X-ray absorptiometry (DXA) in an eldery cohort. https://www.tanita.com/ en/supporting-research

43 Austin MA, Heymsfield SB, Nieman DC. Body composition measurement in females with leg-to-leg bioelectrical impedance analysis compared to dexa. https://www.tanita.com/en/supporting-research

44 Tooze JA, Midthune D, Dodd KW, Freedman LS, Krebs-Smith SM, Subar AF, et al. A new statistical method for estimating the usual intake of episodically consumed foods with application to their distribution. J Am Diet Assoc . 2006;106:1575-87. doi:10.1016/j. jada.2006.07.003. 
45 Sterne JAC, White IR, Carlin JB, et al. Multiple imputation for missing data in epidemiological and clinical research: potential and pitfalls. BMJ 2009:338:b2393. doi:10.1136/bmj.b2393

46 Fine JP, Gray RJ. A Proportional Hazards Model for the Subdistribution of a Competing Risk. J Am Stat Assoc 1999;94:496-509. doi:10.108 0/01621459.1999.10474144.

47 Austin PC, Lee DS, Fine JP. Introduction to the Analysis of Survival Data in the Presence of Competing Risks. Circulation 2016;133:6019. doi:10.1161/CIRCULATIONAHA.115.017719

48 Austin PC, Fine JP. Practical recommendations for reporting Fine-Gray model analyses for competing risk data. Stat Med 2017;36:4391400. doi:10.1002/sim.7501

49 Kohl M, Plischke M, Leffondré K, Heinze G. PSHREG: a SAS macro for proportional and nonproportional subdistribution hazards regression. Comput Methods Programs Biomed 2015;118:218-33. doi:10.1016/i.cmpb.2014.11.009

50 Desquilbet L, Mariotti F. Dose-response analyses using restricted cubic spline functions in public health research. Stat Med 2010;29:1037-57. doi:10.1002/sim.3841

51 Touvier M, Kesse E, Clavel-Chapelon F, Boutron-Ruault M-C. Dual Association of beta-carotene with risk of tobacco-related cancers in a cohort of French women. J Natl Cancer Inst 2005;97:1338-44. doi:10.1093/inci/dji276

52 Norat T, Chan D, Lau R, Aune D, Vieira R. WCRF/AICR systematic literature review continuous Update Project Report. The Associations between Food, Nutrition and Physical Activity and the Risk of Pancreatic Cancer. Imp Coll Lond, 2010.

53 Zamora-Ros R, Béraud V, Franceschi S, et al. Consumption of fruits, vegetables and fruit juices and differentiated thyroid carcinoma risk in the European Prospective Investigation into Cancer and Nutrition (EPIC) study. Int J Cancer 2018;142:449-59. doi:10.1002/ ijc. 30880

54 Wu S, Cho E, Feskanich D, et al. Citrus consumption and risk of basal cell carcinoma and squamous cell carcinoma of the skin. Carcinogenesis 2015;36:1162-8. doi:10.1093/carcin/bgv109

55 Munsell CR, Harris JL, Sarda V, Schwartz MB. Parents' beliefs about the healthfulness of sugary drink options: opportunities to address misperceptions. Public Health Nutr 2016;19:46-54. doi:10.1017/ S1368980015000397

56 Auerbach BJ, Dibey S, Vallila-Buchman P, Kratz M, Krieger J. Review of $100 \%$ Fruit Juice and Chronic Health Conditions: Implications for Sugar-Sweetened Beverage Policy. Adv Nutr 2018;9:78-85. doi:10.1093/advances/nmx006

57 Bellisle F, Hébel P, Fourniret A, Sauvage E. Consumption of 100\% Pure Fruit Juice and Dietary Quality in French Adults: Analysis of a Nationally Representative Survey in the Context of the WHO Recommended Limitation of Free Sugars. Nutrients 2018;10:E459. doi:10.3390/nu10040459

58 Henning SM, Yang J, Shao P, et al. Health benefit of vegetable/ fruit juice-based diet: Role of microbiome. Sci Rep 2017;7:2167. doi:10.1038/s41598-017-02200-6

59 Walker RW, Dumke KA, Goran MI. Fructose content in popular beverages made with and without high-fructose corn syrup. Nutrition 2014;30:928-35. doi:10.1016/j.nut.2014.04.003

60 Atkinson FS, Foster-Powell K, Brand-Miller JC. International tables of glycemic index and glycemic load values: 2008. Diabetes Care 2008;31:2281-3. doi:10.2337/dc08-1239

61 DiMeglio DP, Mattes RD. Liquid versus solid carbohydrate: effects on food intake and body weight. Int J Obes Relat Metab Disord 2000;24:794-800. doi:10.1038/sj.ijo.0801229

62 Ma J, McKeown NM, Hwang S-J, Hoffmann U, Jacques PF, Fox CS. Sugar-Sweetened Beverage Consumption Is Associated With Change of Visceral Adipose Tissue Over 6 Years of Follow-Up. Circulation 2016;133:370-7. doi:10.1161/ CIRCULATIONAHA.115.018704

63 Maersk M, Belza A, Stødkilde-Jørgensen H, et al. Sucrose-sweetened beverages increase fat storage in the liver, muscle, and visceral fat depot: a 6-mo randomized intervention study. Am J Clin Nutr 2012;95:283-9. doi:10.3945/ajcn.111.022533

64 Stanhope KL, Schwarz JM, Keim NL, et al. Consuming fructosesweetened, not glucose-sweetened, beverages increases visceral adiposity and lipids and decreases insulin sensitivity in overweight/ obese humans. J Clin Invest 2009;119:1322-34. doi:10.1172 $\mathrm{JCl} 37385$

65 Doyle SL, Donohoe CL, Lysaght J, Reynolds JV. Visceral obesity, metabolic syndrome, insulin resistance and cancer. Proc Nutr Soc 2012:71:181-9 doi:10.1017/S002966511100320X

66 Augustin LSA, Kendall CWC, Jenkins DJA, et al. Glycemic index, glycemic load and glycemic response: An International Scientific Consensus Summit from the International Carbohydrate Quality Consortium (ICQC). Nutr Metab Cardiovasc Dis 2015;25:795-815 doi:10.1016/j.numecd.2015.05.005

67 Larsson SC, Mantzoros CS, Wolk A. Diabetes mellitus and risk of breast cancer: a meta-analysis. Int J Cancer 2007;121:856-62. doi:10.1002/ijc.22717
68 Lajous M, Boutron-Ruault M-C, Fabre A, Clavel-Chapelon F, Romieu 1. Carbohydrate intake, glycemic index, glycemic load, and risk of postmenopausal breast cancer in a prospective study of French women. Am J Clin Nutr 2008;87:1384-91. doi:10.1093/ajcn/87.5.1384

69 Liu S, Manson JE, Buring JE, Stampfer MJ, Willett WC, Ridker PM. Relation between a diet with a high glycemic load and plasma concentrations of high-sensitivity C-reactive protein in middle-aged women. Am J Clin Nutr 2002;75:492-8. doi:10.1093/ajcn/75.3.492

70 Wang J, Lee I-M, Tworoger SS, et al. Plasma C-reactive protein and risk of breast cancer in two prospective studies and a metaanalysis. Cancer Epidemiol Biomarkers Prev 2015;24:1199-206. doi:10.1158/1055-9965.EPI-15-0187

71 Fedirko V, Lukanova A, Bamia C, et al. Glycemic index, glycemic load, dietary carbohydrate, and dietary fiber intake and risk of liver and biliary tract cancers in Western Europeans. Ann Oncol 2013;24:54353. doi:10.1093/annonc/mds434

72 Uribarri J, Stirban A, Sander D, et al. Single oral challenge by advanced glycation end products acutely impairs endothelial function in diabetic and nondiabetic subjects. Diabetes Care 2007:30:2579-82. doi:10.2337/dc07-0320

73 HCSP. For a public health nutrition policy in France. PNNS 2017 2021. Paris: Haut Conseil de la Santé Publique; 2017. https://www. hcsp.fr/explore.cgi/avisrapportsdomaine?clefr $=657$

74 World Cancer Research Fund/American Institute for Cancer Research Continuous Update Project Expert Report 2018. Recommendations and public health and policy implications. https://www.wcrf.org/ dietandcancer

75 Mostafalou S, Abdollahi M. Pesticides: an update of human exposure and toxicity. Arch Toxicol 2017;91:549-99. doi:10.1007/s00204016-1849-x

76 Soffritti M, Belpoggi F, Tibaldi E, Esposti DD, Lauriola M. Lifespan exposure to low doses of aspartame beginning during prenatal life increases cancer effects in rats. Environ Health Perspect 2007;115:1293-7. doi:10.1289/ehp.10271

77 M S, M P, e T, et al. Sucralose administered in feed, beginning prenatally through lifespan, induces hematopoietic neoplasias in male swiss mice. Int J Occup Environ Health 2016;22:7-17. doi:10.1 080/10773525.2015.1106075

78 Toews I, Lohner S, Küllenberg de Gaudry D, Sommer H, Meerpoh II. Association between intake of non-sugar sweeteners and health outcomes: systematic review and meta-analyses of randomised and non-randomised controlled trials and observational studies. BM/ 2019:364:k4718 doi:10.1136/bmi.k4718

79 Andreeva VA, Salanave B, Castetbon K, et al. Comparison of the sociodemographic characteristics of the large NutriNetSante e-cohort with French Census data: the issue of volunteer bias revisited. J Epidemiol Community Health 2015;69:893-8. doi:10.1136/jech-2014-205263

80 ANSES. Etude Individuelle Nationale des Consommations Alimentaires 3 (INCA 3). 2017. https://www.anses.fr/fr/system/files/ NUT2014SA0234Ra.pdf

81 Willett W. Nutritional Epidemiology. Vol. 2nd. Oxford University Press, 1998. doi:10.1093/acprof:oso/9780195122978.001.0001

82 Hu FB, Satija A, Rimm EB, et al. Diet Assessment Methods in the Nurses' Health Studies and Contribution to EvidenceBased Nutritional Policies and Guidelines. Am J Public Health 2016;106:1567-72. doi:10.2105/AJPH.2016.303348

83 Ahluwalia N, Dwyer J, Terry A, Moshfegh A, Johnson C. Update on NHANES Dietary Data: Focus on Collection, Release, Analytical Considerations, and Uses to Inform Public Policy. Adv Nutr 2016;7:121-34. doi:10.3945/an.115.009258

84 Lassale C, Castetbon K, Laporte F, et al. Validation of a Web-based, self-administered, non-consecutive-day dietary record tool against urinary biomarkers. Br J Nutr 2015;113:953-62. doi:10.1017/ S0007114515000057

85 Lassale C Castetbon K, Laporte F Deschamps V, Vernay M, Camilleri GM, et al, Correlations between Fruit, Vegetables, Fish, Vitamins, and Fatty Acids Estimated by Web-Based Nonconsecutive Dietary Records and Respective Biomarkers of Nutritional Status. J AcadNutrDiet. 2016;116:427-38. doi:10.1016/j.jand.2015.09.017

86 Barreira TV, Harrington DM, Staiano AE, Heymsfield SB, Katzmarzyk PT. Body adiposity index, body mass index, and body fat in white and black adults. JAMA 2011;306:828-30. doi:10.1001/ jama.2011.1189

87 HCSP. Pour une Politique nutritionnelle de santé publique en France. PNNS 2017-2021. Paris: Haut Conseil de la Santé Publique; 2017. https://www.hcsp.fr/explore.cgi/avisrapportsdomaine?clefr=632

88 World Cancer Research Fund International. Building momentum: lessons on implementing a robust sugar sweetened beverage tax. https://www. wcrf.org/sites/default/files/PPA-Building-Momentum-Report.pdf

89 Colchero MA, Popkin BM, Rivera JA, Ng SW. Beverage purchases from stores in Mexico under the excise tax on sugar sweetened beverages: observational study. BMJ 2016;352:h6704. doi:10.1136/bmj.h6704

Supplementary materials: Appendix 1 to 13 